\title{
Social policy for social work and human services in Aotearoa New Zealand: Diverse perspectives
}

\author{
Jane Maidment and Liz Beddoe (Eds.) \\ Canterbury University Press, Christchurch, 2016 \\ ISBN 978-1-927145-73-9, pp. 356, Paperback, NZ\$45.00
}

$\mathrm{T}$ This book is a welcome addition to the Aotearoa New Zealand social policy literature. Jane Maidment and Liz Beddoe have pulled together a range of contributors and therefore, the contents cover a diverse scope of perspectives on current social policy issues. The book is divided into three sections. It is impossible in a short book review to comment on all chapters, no matter how good, so this review by commenting on a selected few chapters is in no way implying that they are better than other chapters. From the outset it becomes apparent that although the book will be very useful for a student audience, the depth of analysis makes this book a resource for experienced practitioners as well.

The first section of the book broadly outlines social policy and the key policy discourses within Aotearoa New Zealand. The section draws on a range of sociological traditions to contextualise current social policy: Alan Bartley, for example revisits C Wright Mills' sociological imagination and Durkheim's social rules. Liz Beddoe moves from conventional sociological traditions to discuss how moral panic and the media also shape social policy.Of particular note, particularly for students, is the chapter by Nicky Stanley-Clarke. This chapter gives a very clear exposition of the different theoretical/philosophical positions and ideologies that have historically shaped social policy. The section firmly places Te Tiriti central to a discussion of social policy in Aotearoa New Zealand. Further, Yvonne Crichton-Hill's chapter discusses the role of social policy in enhancing the wellbeing of Pasifika people.

The second section on policy perspectives contains ten chapters. Each chapter addresses policy in a particular area of practice relevant to social work and human services. What impressed my most about this section was the diversity of perspectives addressed. Perspectives on aged care, disability child protection and the impact of health policy on Māori would be expected in any text covering social policy in Aotearoa New Zealand. However, the editors have ensured that the book includes commentary on very real issues confronting us as a country at the moment: issues such as refugees and informal caregivers. John Fenaughty and Frank Pega discuss a range of issues relating to gender and sexually diverse people and how difficulty identifying this population is a challenge for social policy fairness and effectiveness. The case studies on school safety and health care within this chapter highlight access and resourcing issues remain, even if policy is appropriate. Irene de Haan's chapter on family violence has a focus on two forms of family violence - intimate partner violence and child maltreatment. A notable omission in the discussion is the issue of elder abuse. Although Glynnis Brook, on her chapter on aged care policy mentions her own research in this area, policy in this area appears lacking.

The six chapters in the final section in the book look at some examples of how practitioners can engage with social policy to facilitate social action and/or social change. The first 
two are good examples of the intersection of environment with policy. Clean water and adequate healthy food are essential needs but income, which is often seen as the sole measure of poverty is not the only factor influencing a population's access to these. Giles discusses traditional land rights, geographical and environmental factors as well as a range of sociocultural factors that play a part.
Overall, this book is an excellent addition to any social worker's library. The range of authors, both practitioners and academics make social policy understandable and accessible to the reading audience. If I was to identify any gap it would be around social policy relating to professionalisation and how this is playing out in Aotearoa New Zealand.

Reviewed by Jan Duke Social Workers Registration Board 